\title{
Enrichment of putative human epidermal stem cells based on cell size and collagen type IV adhesiveness
}

\author{
Juxue $\mathrm{Li}^{1,2}$, Chenglin Miao ${ }^{1,2}$, Weixiang Guo ${ }^{1,2}$, Liwei $\mathrm{Jia}^{1,2}$, Jiaxi Zhou ${ }^{1,2}$, Baohua Ma ${ }^{1}$, Sha Peng ${ }^{1,2}$, \\ Shuang Liu ${ }^{1,2}$, Yujing Cao ${ }^{1}$, Enkui Duan ${ }^{1}$ \\ ${ }^{1}$ State Key Laboratory of Reproductive Biology, Institute of Zoology, Chinese Academy of Sciences, Datun Road, Chaoyang Dis- \\ trict, Beijing 100101, China; ${ }^{2}$ Graduate School of the Chinese Academy of Sciences, 19 Yuquan Road, Beijing 100039, China
}

The enrichment and identification of human epidermal stem cells (EpSCs) are of paramount importance for both basic research and clinical application. Although several approaches for the enrichment of EpSCs have been established, enriching a pure population of viable EpSCs is still a challenging task. An improved approach is worth developing to enhance the purity and viability of EpSCs. Here we report that cell size combined with collagen type IV adhesiveness can be used in an improved approach to enrich pure and viable human EpSCs. We separated the rapidly adherent keratinocytes into three populations that range in size from 5-7 $\mu \mathrm{m}$ (population A), to 7-9 $\mu \mathrm{m}$ (population B), to $\geq 9 \mu \mathrm{m}$ (population $\mathrm{C}$ ) in diameter, and found that human putative EpSCs could be further enriched in population A with the smallest size. Among the three populations, population A displayed the highest density of $\beta 1$ integrin receptor, contained the highest percentage of cells in G0/G1 phase, showed the highest nucleus to cytoplasm ratio, and possessed the highest colony formation efficiency (CFE). When injected into murine blastocysts, these cells participated in multi-tissue formation. More significantly, compared with a previous approach that sorted putative EpSCs according to $\beta 1$-integrin antibody staining, the viability of the EpSCs enriched by the improved approach was significantly enhanced. Our results provide a putative strategy for the enrichment of human EpSCs, and encourage further study into the role of cell size in stem cell biology.

Keywords: epidermal stem cells, collagen type IV, cell size, $\beta 1$-integrin

Cell Research (2008) 18:360-371. doi: 10.1038/cr.2007.103; published online 11 December 2007

\section{Introduction}

The human epidermis represents a constantly renewing, stratified squamous epithelium that is mainly composed of keratinocytes organized into distinct cellular layers [1]. The basal layer of the epidermis contains a small population of self-renewing cells that have high proliferative potential, named the epidermal stem cells (EpSCs), and their progeny of transient amplifying (TA) cells that have limited proliferative potential $[2,3]$. There has been growing interest in research into EpSCs and their roles in homeostasis, wound repair and tumorigenesis. EpSCs are also becoming attractive as a therapeutic

Correspondence: Enkui Duan

Tel: +86-10-64807308; Fax: +86-10-64807186

E-mail: duane@ioz.ac.cn

Received 19 July 2007; revised 13 September 2007; accepted 30 September 2007; published online 11 December 2007 option in tissue bioengineering, gene therapy and the treatment of a variety of diseases [4-9]. Because EpSCs are important for both basic research and clinical application, establishing an approach to separate EpSC populations from the epidermis is of paramount importance.

Although there are already several established approaches for the enrichment of EpSCs [2, 10-13], isolating a population of pure and viable putative EpSCs is still problematic. Previous attempts to separate EpSCs from TA cells did not result in the identification of a specific marker. In human skin and limbal epithelium, $\beta 1$ integrin has been accepted as a basal cell marker that is associated with certain stem cell properties $[2,14]$. Human EpSCs can be directly enriched from keratinocytes owing to the high surface area of $\beta 1$-integrin and the rapidly adherence to the $\beta 1$-integrin ligand collagen type IV (using an adhesion-selection approach) [2]. However, questions about the purity of the enriched EpSCs in $\beta 1$ integrin bright populations have arisen. The proportion of 
$\beta 1$-integrin bright cells in the basal layer of the epidermis ranges from $25 \%$ in palm cells to $\geq 40 \%$ in foreskin and scalp cells [15], which is at least double the proportion that is estimated to be stem cells in vivo [16]. $\beta 1$-integrin bright cells are likely to include stem cells as well as a significant number of TA cells. Further selection using other parameters is necessary to obtain a more enriched population. Other studies have suggested that a keratinocyte population containing stem cells could be enriched based on the high level of integrin- $\alpha 6$ expression and the low level of CD71 expression $\left(\alpha 6^{\text {bri }} \mathrm{CD} 71^{\mathrm{dim}}\right)[10,12$, 17]. This approach was thought to be useful for enriching the most well-characterized EpSCs. However, there are also limitations associated with this approach. First, the phenotype of $\alpha 6^{\text {bri }} \mathrm{CD} 71^{\text {dim }}$ was defined as an arbitrarily boxed region on a flow cytometric plot and no definite boundaries were suggested for stem cells, TA cells and differentiated cells. Second, $\alpha 6^{\text {bri }} \mathrm{CD} 71^{\text {bri }}$ cells and $\alpha 6^{\text {dim }}$ cells were reported to be capable of prolonged tissue regeneration [18], indicating that EpSCs also exist in committed keratinocyte populations. Third, the cell viability in the staining process should be considered. Recently, a murine keratinocyte side population was reported to exhibit the phenotypic and functional characteristics of EpSCs [19-21]. However, the results from human keratinocyte side populations are conflicting and need to be further validated $[22,23]$. Collectively, enriching a population of EpSCs with high purity and viability is still a challenging task and so exploring improved approaches is of value.

In our previous studies, we have enriched human EpSCs through fluorescence-activated cell sorting (FACS) based on high levels of $\beta 1$-integrin [13]. Owing to the lengthy duration of the antibody staining process, we found that the viability of cells sorted using this approach was low. As an alternative, we enriched $\beta 1$-integrinbright cells that had high viability using the adhesionselection approach. Under microscopy, these cells displayed heterogeneity in their cell sizes. Whether the $\beta 1$ integrin-bright cell population could be further enriched for even more potent EpSCs by combing with cell size selection was intriguing.

It has been reported that cell size correlates with proliferation ability in human keratinocytes, corneal cells and fibroblasts [24-29]. Human keratinocytes and corneal cells with the smallest cell size show the highest colony formation efficiency (CFE) [25, 29]. Given that one of the characteristics of adult stem cells is that they are always smaller in size in contrast to more differentiated cells, we hypothesized that the smallest rapidly adherent (RA) cells are a subpopulation of keratinocytes that are enriched for the most potent EpSCs. We separated the
RA cells into three populations, ranging in size from 5 $-7 \mu \mathrm{m}$ (population A), to 7-9 $\mu \mathrm{m}$ (population B), to $\geq$ $9 \mu \mathrm{m}$ (population $\mathrm{C}$ ) in diameter. We found that population A with the smallest size did in fact represent a more enriched population of human EpSCs and showed more characteristics of EpSCs. Moreover, compared with our previous approach that sorted putative EpSCs based on $\beta 1$-integrin staining, the viability of the EpSCs enriched by the improved approach was significantly enhanced. Our results demonstrated that collagen type IV adhesiveness combined with cell size was an improved approach to enrich human EpSCs.

\section{Results}

$R A$ cells represent the high p63-expressing cells in the epidermal basal layer and can be further separated on the basis of cell size

P63 transcription factor, a p53 homolog, has been shown to be an epidermal stem cell associated marker [30]. It helps to distinguish human keratinocyte progenitor cells from their more differentiated cells. We stained RA, slowly adherent (SA) and never-adherent (NA) cells with p63 antibody under the same conditions and examined p63 expression under a confocal microscope using the same parameters. We found that most of the RA cells expressed high levels of p63 protein (Figure 1A and 1D), thus representing the high $\mathrm{p} 63$-expressing cells in the epidermal basal layer (Figure $1 \mathrm{G}$ and $1 \mathrm{H}$ ). By contrast, SA cells (Figure 1B and 1E) and NA cells (Figure 1C and $1 \mathrm{~F}$ ) represented the low p63-expressing cells and the p63-negative cells in the basal layer and superlayer (Figure $1 \mathrm{G}$ and $1 \mathrm{H}$ ), respectively. These findings show that RA cells are enriched for less differentiated progenitor cells from the basal layer.

To investigate whether the RA cells (adhered within $20 \mathrm{~min}$ ) had different forward scatter (FSC) characteristics compared with other basal cells, we analyzed the adhesion properties of keratinocytes with collagen type IV adherence for different lengths of time (10, 20, 30, 60 and $90 \mathrm{~min}$ ) and compared the light-scattering properties using flow cytometric analysis. We found that the percentages of basal keratinocytes that adhered to collagen type IV were positively related to the adhesion time (Figure 2A). However, RA cells did not significantly differ from other basal cells in their FSC characteristics (Figure 2B).

Under the microscope, RA cells exhibited different cell sizes (Figure 2C). The cell sizes of RA cells ranged from 5 to $16 \mu \mathrm{m}$ in diameter. Population A accounts for $21.6 \pm 1.23 \%$ of RA cells, and the other two populations, poulation $\mathrm{B}$ and population $\mathrm{C}$, with their increasing sizes, 


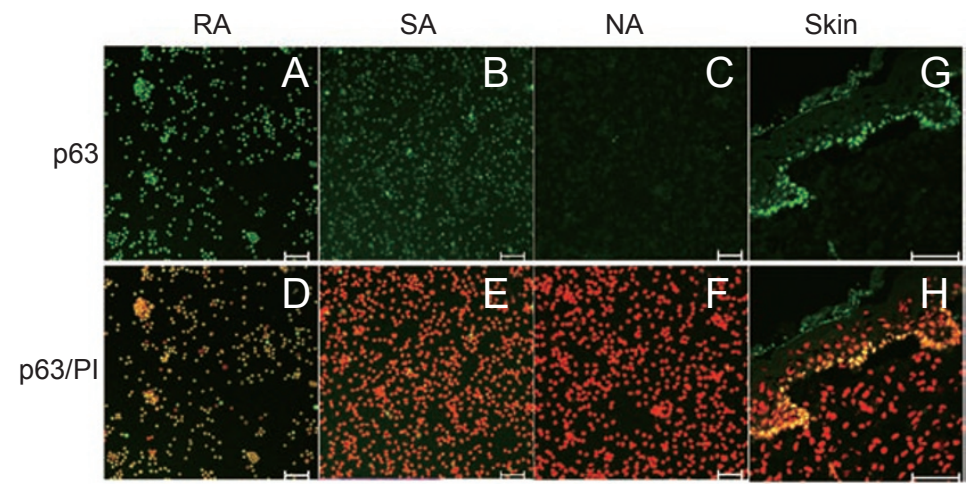

Figure 1 P63 expression in separated keratinocyte populations and in skin tissue. (A-F) Expression of the p63 protein (green) in RA, SA and NA cells, which represent the high p63-expressing cells, low p63-expressing cells and p63-negative cells in the epidermis ( $\mathbf{G}$ and $\mathbf{H})$. Red represents propidium iodide. The scale bar represents $50 \mu \mathrm{m}$.

A

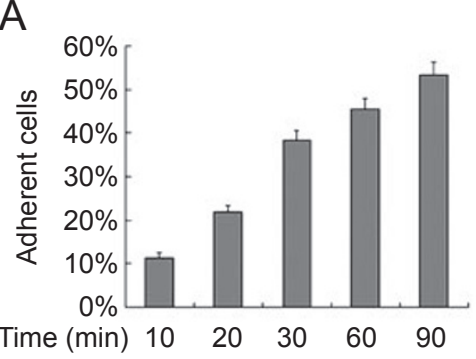

B

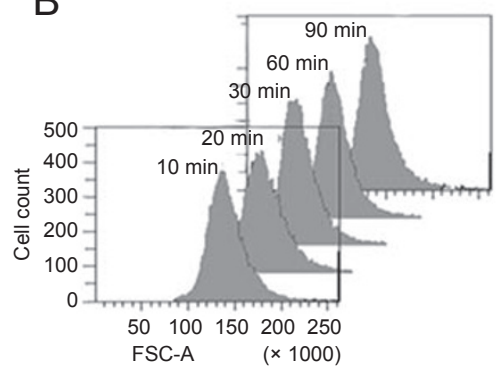

C

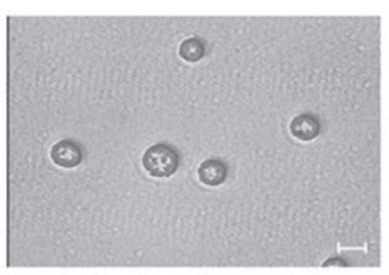

D

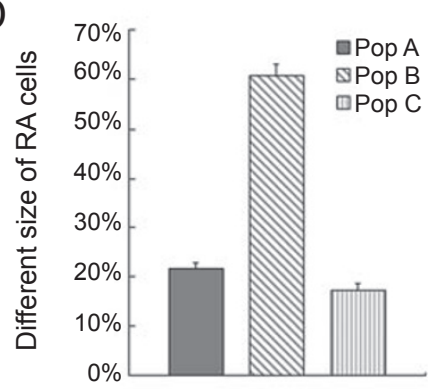

E

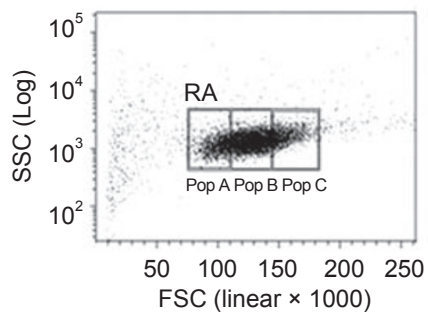

$\mathrm{F}$

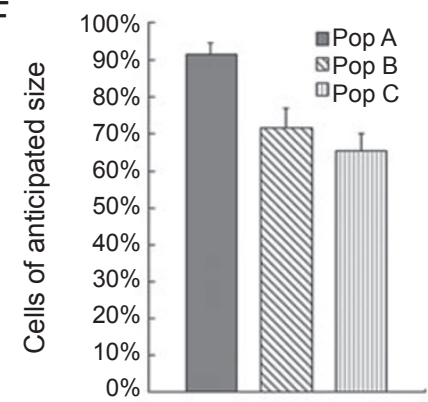

Figure 2 RA cells can be further separated on the basis of cell size. (A) The percentages of human keratinocytes that adhered to collagen type IV for different lengths of time. (B) A histogram of the distribution of FSCs of human keratinocytes isolated according to different lengths of adherent time. (C) RA cells show different cell sizes ( $\times 400)$. (D) Percentages of RA cells sorted according to different size ranges. (E) Flow cytometric analysis of RA cells, which were selected by cell size sorting. (F) Percentages of sorted cells (population A, population B and population C) according to anticipated cell size.

account for $60.6 \pm 2.57 \%$ and $17.3 \pm 1.42 \%$, respectively (Figure 2D). Based on an FSC profile and their relative percentages, we sorted the RA cells into three populations (population A, population B and population C) (Figure 2E). We measured the diameter of the sorted cells under the microscope and found that most cells in population A $(91.7 \pm 3.2 \%)$ had a diameter of 5 to $7 \mu \mathrm{m}$ (Figure 2F), indicating that the smallest RA cells could be enriched using this method.
Population A, with the smallest cell size, contains significantly more cells in G0/G1 phase and shows the highest nuclear to cytoplasmic ratio, thus confirming the sorting

To investigate the cycling status of the three size-selected populations, each population was stained with PI for flow cytometric analysis. The results obtained from three independent experiments demonstrated that cells from population A contained significantly more cells in G0/G1 phase $(97.46 \% \pm 0.93 \%)$ compared with popula- 
tion B $(93.16 \pm 1.29 \%, P<0.05)$ and population $\mathrm{C}(81.79$ $\pm 1.47 \%, P<0.01$ ) (Figure 3A). By contrast, population B and population $\mathrm{C}$ were significantly enriched for actively cycling cells, compared with population A, which contained markedly fewer cells in the $\mathrm{S}$ and $\mathrm{G} 2 / \mathrm{M}$ phases $(P<0.05)$. We analyzed the three sorted cell populations using transmission electron microscopy. We found that population A had a 'blast-like' appearance (Figure 3B), with the fewest cytoplasmic organelles and the smallest cytoplasmic space. Also, cells from population A had the highest nuclear to cytoplasmic ratio (Figure 3C). Cells were typically smallest in G0/G1 phase, and sorting for cell size again selected the cells in $\mathrm{S}$ and $\mathrm{G} 2 / \mathrm{M}$ phases. Also, the smaller cells had a higher nuclear to cytoplasm ratio because the nucleus size had changed less than the cytoplasm volume. As a result, these findings confirm that sorting occurs. However, in our data obtained from mice (unpublished data), we found that the smaller cells were enriched for significantly more BrdU label-retaining cells, which partly suggests that cells from population $\mathrm{A}$ are quiescent.

Population A, with the smallest cell size, exhibits the highest membrane density of the $\beta 1$-integrin receptor

We carried out flow cytometric analysis to examine the fluorescence of the three sorted populations to investigate whether cells from population A had the highest $\beta 1$-integrin protein expression. As shown in Table 1, we found that there was no significant difference in the fluorescence levels of the three populations. Given that the flow cytometer measures the total fluorescence of a cell rather than the fluorescence per unit area and a larger cell with a lower level of $\beta 1$-integrin on the cell surface could have the same fluorescence as a smaller cell with a higher level of surface $\beta 1$-integrin, we measured the average diameter of the cells in the three sorted subpopulations and calculated the relative receptor density of $\beta 1$ integrin. We found that population $\mathrm{A}$, with the smallest cell size, had the highest density of the $\beta 1$-integrin receptor.

\section{Population A, with the smallest cell size, has the highest CFE}

We investigated the proliferative ability of cell populations selected according to adherence to collagen type IV. Figure 4A and 4B summarizes the CFEs from three independent experiments. The highest $\mathrm{CFE}$ was seen in the RA cells $(27.2 \pm 0.73 \%)$, which is significantly higher than that of unfractionated cells $(6.8 \pm 0.23 \%$, $P<0.01)$, and the SA cells $(8.13 \pm 0.42 \%, P<0.01)$. Few
A

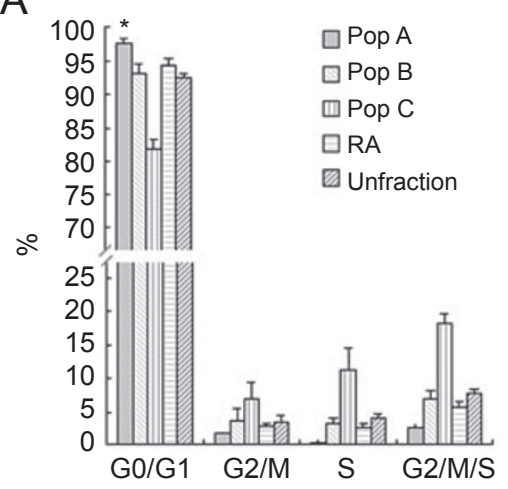

B

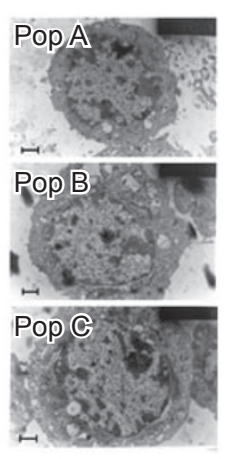

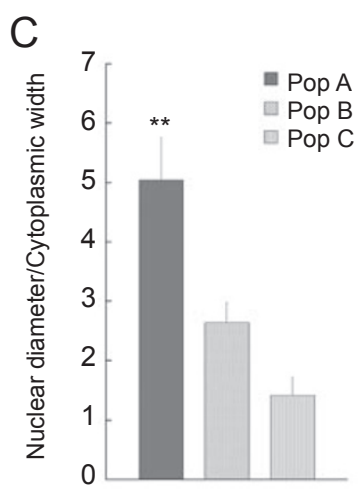

Figure 3 Cell-cycle analysis and transmission microscope images. (A) Cell-cycle analysis of primary fractionated basal keratinocytes. The data shown are the mean values \pm the S.D. ${ }^{*} P<0.05$. (B) Representative transmission microscope images of separated RA cells ( $\times 8000)$. (C) Nuclear to cytoplasmic ratio of separated RA cells. ${ }^{* *} P<0.01$.

Table 1 Cell size and intensity of the $\beta 1$-integrin subunit in FACS-sorted RA cells

\begin{tabular}{llll}
\hline Sorted group & $\begin{array}{l}\text { Mean cell diameter } \\
(\mu \mathrm{m} \pm \mathrm{SEM})\end{array}$ & $\begin{array}{l}\text { Mean } \beta 1 \text { fluorescence } \\
\text { (arbitrary units) }\end{array}$ & $\begin{array}{l}\text { Relative fluorescence } \\
\text { intensity }\end{array}$ \\
\hline Population A & $5.91 \pm 0.26$ & 1017 & 29.12 \\
Population B & $7.58 \pm 0.36$ & 1025 & 17.83 \\
Population C & $9.14 \pm 0.23$ & 1023 & 12.25 \\
\hline
\end{tabular}

Data shown as the mean \pm S.D. 
colonies were observed in the NA cells. Consistent with a previous study [2], these data suggest that RA cells are enriched for EpSCs.

To evaluate the cell growth capacity of each sizeselected population from RA cells, we carried out a CFE assay. The highest CFE was observed in cells from population A $(38.8 \pm 1.9 \%)$, which is significantly higher than those of unsorted RA cells $(27.2 \pm 0.73 \%, P<0.05)$, cells from population $\mathrm{B}(26.8 \pm 6.2 \%, P<0.05)$ and cells from population $\mathrm{C}(19.8 \pm 1.8 \%, P<0.01)$ (Figure $4 \mathrm{C}$ and $4 \mathrm{D})$. Together, these data indicate that the smallest RA cells possess the highest CFEs.

Population A, with the smallest cell size, can undergo terminal differentiation in suspension culture

To investigate whether cells from population A can undergo terminal differentiation, we cultured cells from population $\mathrm{A}$ in FD culture media containing $1.6 \%$ methyl cellulose for $24 \mathrm{~h}$. In the medium, the cells were deprived of substratum and intercellular contact, in order to induce terminal differentiation. We examined the expression of two epidermal cell related markers - $\beta 1$ integrin, a marker for EpSCs, and involucrin, a terminal differentiation marker for keratinocytes - in both un-induced population A cells and induced population A cells. Before the induced culture, we found that the population A cells did not express involucrin (Figure 5Aa and 5Ab). However, after $24 \mathrm{~h}$ induced culture, involucrin expression could be found in population A cells (Figure 5Ac and 5Ad). By contrast, population A cells expressed $\beta 1$ integrin before induced culture (Figure $5 \mathrm{Ba}$ and $5 \mathrm{Bb}$ ) and did not express $\beta 1$-integrin after induced culture
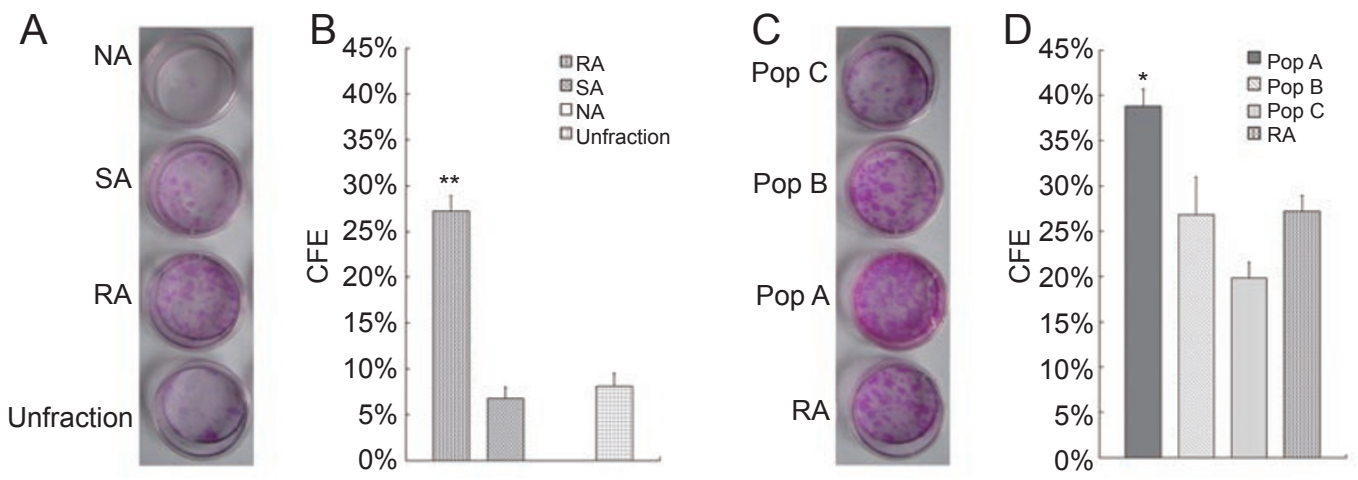

Figure 4 The CFE of fractionated keratinocytes. (A and C) Representative cultures of keratinocyte populations separated by collagen type IV adhesiveness (NA, SA and RA cells) and size-sorted RA cells (population A, population B and population C cells). (B and D) The CFE of adherent separated keratinocytes and size-sorted RA cells. The CFE values are shown as the mean \pm S.D. ${ }^{*} P<0.05,{ }^{* *} P<0.01$.
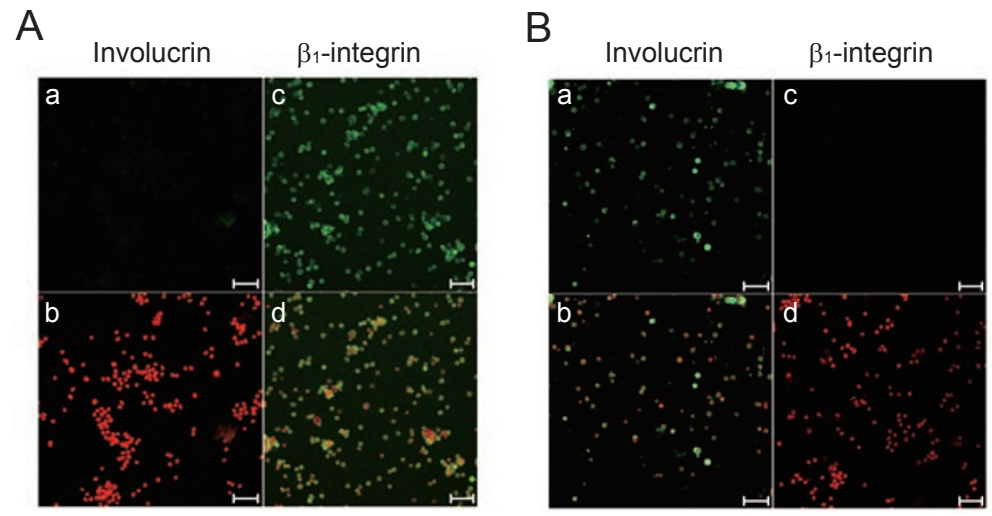

Figure 5 Population A cells undergo terminal differentiation in suspension culture. (A) Before induction, cells from population A did not express involucrin ( $a$ and b) and expressed $\beta 1$-integrin (green) (c and d). (B) After $24 \mathrm{~h}$ of induction, the induced cells from population A expressed involucrin (green) ( $a$ and b) and lost the expression of $\beta 1$-integrin (c and d). Red represents propidium iodide. The scale bar represents $50 \mu \mathrm{m}$. 
A

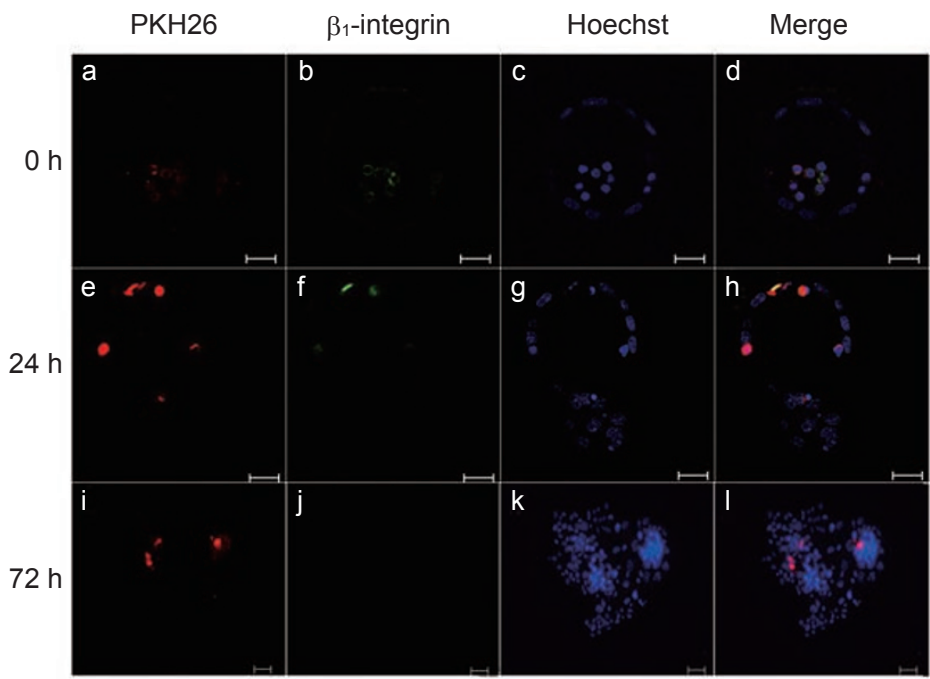

B

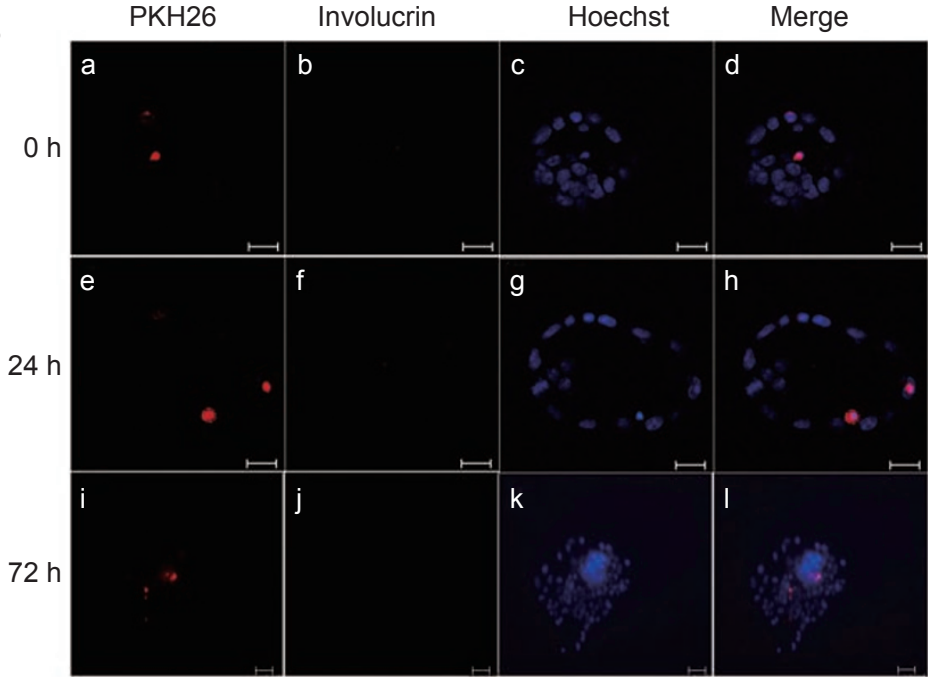

C

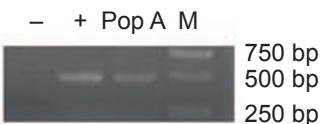

D

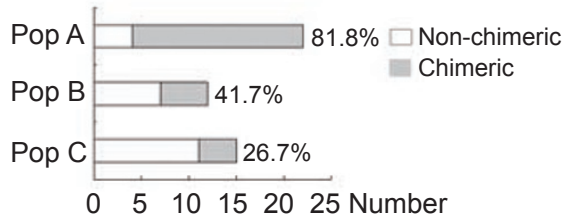

E

F
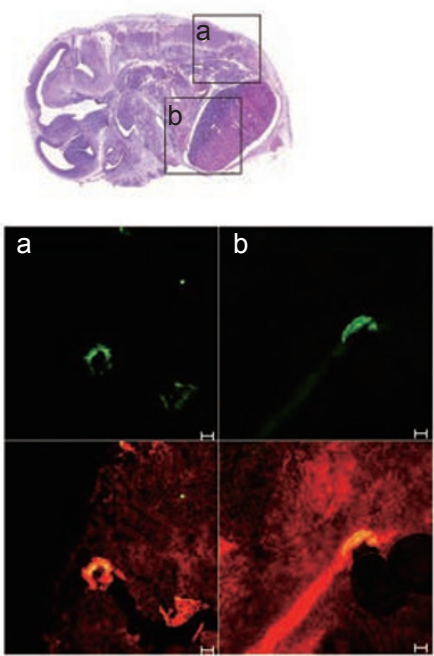

G

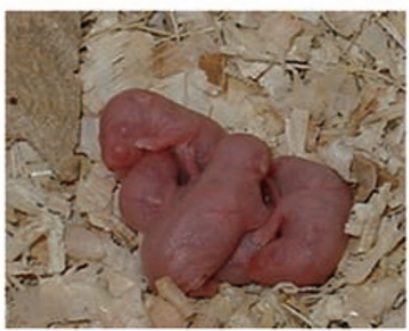

$\mathrm{H}$

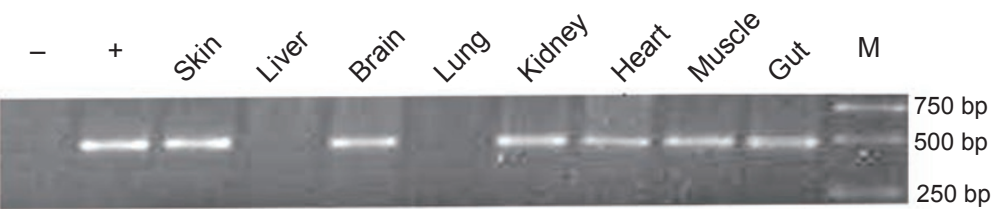

Figure 6 Population A cells differentiate in murine blastocysts and are incorporated into murine tissues. (A) Expression of $\beta 1$ integrin (green) in cells from population A (red, stained with $\mathrm{PKH} 26$ ) injected into blastocysts (counterstained with Hoechst) at $0 \mathrm{~h}(\mathrm{a}-\mathrm{d}), 24 \mathrm{~h}(\mathrm{e}-\mathrm{h})$ and $72 \mathrm{~h}(\mathrm{i}-\mathrm{I})$. (B) Expression of involucrin (green) in cells from population A (red, stained with PKH26) injected into blastocysts (counterstained with Hoechst) at $0 \mathrm{~h}(\mathrm{a}-\mathrm{d}), 24 \mathrm{~h}(\mathrm{e}-\mathrm{h})$ and $72 \mathrm{~h}$ (i-I). (C) PCR shows that there were human donor cells present in embryos derived from blastocysts injected with cells from population A. M represents markers; + represents positive control; - represents negative control. (D) A histogram showing the ratio of chimeric embryos derived from injected blastocysts. (E) Day 13.5 embryo section stained with hematoxylin and eosin. Inset boxes a and b correspond to $a$ and $b$ in part (F). (F) Human donor cells (green) were found in vertebrae (a) and brain (b). (G) Live mice derived from blastocysts injected with cells from population A. (H) A representative PCR showing human donor cells present in many tissue types in the adult mouse at the age of 2 months. In the representative mouse, human donor cells existed in the skin, brain, kidney, heart, muscle and gut, but not in the liver and lung. Red represents propidium iodide. The scale bar represents $20 \mu \mathrm{m}$. 
(Figure $5 \mathrm{Bc}$ and $5 \mathrm{Bd}$ ). These results suggest that cells from population A can undergo terminal differentiation similar to normal EpSCs.

Population A, with the smallest cell size, is incorporated into murine tissues during murine embryo development

To further explore the activity of the enriched EpSCs, we stained the cells from population A with the red fluorescent dye PKH26 and carried out blastocyst injection assays. We cultured the blastocyst-injected cells from population A in vitro for different lengths of time $(0,24$ and $72 \mathrm{~h}$ ) and analyzed the expression of $\beta 1$-integrin and involucrin at each time point. To analyze $\beta 1$-integrin expression, five blastocyts, four blastocyts and six blastocyts were examined at 0,24 and $72 \mathrm{~h}$, respectively. To analyze involucin expression, six blastocysts, five blastocysts and six blastocysts were examined at 0,24 and $72 \mathrm{~h}$, respectively. We found that cells from population A expressed $\beta 1$-integrin at $0 \mathrm{~h}$ (Figure 6Aa-d) and at $24 \mathrm{~h}$ of culture (Figure 6Ae-h). However, $\beta 1$-integrin expression was not observed at $72 \mathrm{~h}$ (Figure 6Ai-1). Furthermore, the blastocyst-injected cells from population A did not express involucrin at $0 \mathrm{~h}$ (Figure 5Ba-d), $24 \mathrm{~h}$ (Figure 6Be-h) or $72 \mathrm{~h}$ (Figure 6Bi-1). These results show that cells from population A can differentiate in murine blastocysts.

To extend our in vitro results, cells from each of the three populations were injected into blastocysts. The injected blastocysts were transferred to recipients. At embryonic day 13.5, embryos were harvested from the recipient uteri and examined for the existence of human donor cells. We found that human donor cells existed in the murine embryos (Figure 6C). Figure 6D summarizes the ratio of chimeric embryos derived from injected blastocysts. In most samples $(18 / 22,81.8 \%)$ derived from blastocysts injected with cells from population $\mathrm{A}$, the existence of human donor cells could be detected. By contrast, fewer donor cells could be detected in embryos injected with cells from population B $(5 / 12,41.7 \%)$ and cells from population $\mathrm{C}(4 / 15,26.7 \%)$. To further demonstrate the existence of human cells in the chimeric embryos, we performed immunohistochemical analysis and found that cells stained positive for anti-human antibody existed in the chimeric embryos. Since only 20-25 human cells were injected into each blastocyst and many more positive cells were found in the murine tissues, these findings demonstrate that human cells can survive and proliferate in mouse embryos during development. Furthermore, human donor cells can take part in the formation of several murine tissues, such as vertebrae (Figure 6Ea and $6 \mathrm{Fa}$ ) and brain (Figure 6Eb and 6Fb). Also, we obtained live mice from blastocyst-injected cells from population A (Figure 6G). We found that human donor cells existed in many tissues of the adult mice at the age of 2 months. Figure $6 \mathrm{H}$ shows a representative PCR detection from one chimeric mouse. In the representative mouse, human donor cells existed in the skin, brain, kidney, heart, muscle and gut, but not in the liver and lung. Together, these results indicate that cells from popualtion A possess the greatest proliferation and differentiation potential and can participate in mouse multitissue formation.

Population A, with the smallest cell size, shows higher viability compared with the $\beta 1$-integrin bright cell population isolated using antibody-based FACS ( $\beta 1$-IBCPIAF)

In our previous studies, we have found that $\beta 1$ integrin bright cell populations that are isolated using FACS always show low viability, which is probably due to the antibody staining process. In this study, we investigated whether human putative EpSCs that are enriched using our improved strategy can survive better than the
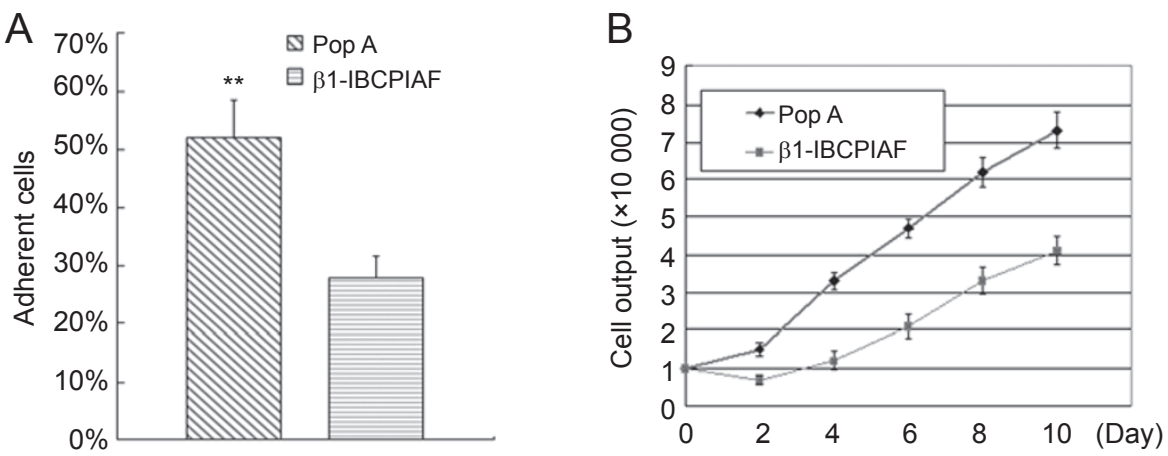

Figure 7 Cell viability of population A cells and $\beta 1$-IBCPIAF cells. (A) Percentages of adhered cells in the population A cell population and in the $\beta 1$-IBCPIAF cell population. (B) Growth curve of population A cells and $\beta 1$-IBCPIAF cells in short-term culture. ${ }^{* *} P<0.01$ 
$\beta 1$-IBCPIAF cells. We plated an equal number of population A cells and $\beta 1$-IBCPIAF cells onto collagen type IV-coated plates without feeder cells. The percentages of adherent cells were assessed after $12 \mathrm{~h}$. We found that cells from population A survived much better than $\beta 1$ IBCPIAF cells (Figure7A). During propagation, the cells from population A proliferated much faster (Figure 7B). After 10-day culture, we harvested nearly twice as many cells from population A (Figure 7B).

\section{Discussion}

Previous studies have suggested that human putative EpSCs could be enriched on the basis of their high surface expression of $\beta 1$-integrin and their rapid adherence to collagen type IV $[2,13,31]$. In our experiments, we found that RA cells with high $\beta 1$-integrin expression were also high p63-expressed cells, indicating that RA cells are primitive cells in the basal layer. Given that one of the characteristics of adult stem cells is the small size, we carried out flow cytometric analysis to investigate whether the RA cells were smaller in cell size than other basal cells. We found that RA cells did not significantly differ from other basal keratinocytes in their FSC characteristics. However, previous studies have demonstrated that cell size is related to cell-cycle characteristics [24], cell proliferation $[25,26,29]$ and cell differentiation $[27$, 32-35]. The proliferative potential of human fibroblasts, keratinocytes and corneal cells was shown to be inversely dependent on cell size [25, 29]. Based on these findings, we reasoned that the subpopulation of keratinocytes that have the smallest size in RA epidermal cells were good candidates to be enriched for EpSCs.

We carried out cell sorting and in vitro identification, as well as functional tests to investigate whether the smallest cells (5-7 $\mu \mathrm{m}$, population A) in the RA cell population satisfied several characteristic features of EpSCs in morphology, phenotype and growth potential. These features included slow cycling or long cell-cycle time during homeostasis in vivo, small size with poor differentiation and primitive cytoplasm, and high proliferative potential in culture [36, 37]. Among the three populations that were selected from RA cells on the basis of size, population A, with the smallest cell size, was found to contain the highest percentage of cells in the G0/G1 phase, which confirms our sorting because the cells in G1 phase are typically small in cell size. However, in our data obtained from the mouse (unpublished data), we found that the smaller cells were enriched for significantly more BrdU label-retaining cells, which partly supports the idea that population $\mathrm{A}$ is a quiescent subpopulation in the epidermal basal layer. The localization of cells from population A to the epidermal basal layer, a site proposed for slow-cycling interfollicle EpSCs, further strengthens our hypothesis [38]. In addition, these cells display a primitive cell morphology with a higher nuclear to cytoplasmic ratio, which confirms our sorting because the nucleus size changes less than the cytoplasm volume in smaller cells. Also, a higher nuclear to cytoplasmic ratio is supposed to be a putative stem cell trait. Our data also show that the candidate keratinocyte stem cell fraction represents a minor subpopulation (4\%) in the basal layer cells, which is consistent with the estimation of $1-10 \%$ from kinetic studies in the murine epidermis [39-42]. We found that the size-selected populations did not significantly differ in the total level of $\beta 1$-integrin expression. However, when calculating the unit density of the $\beta 1$ integrin receptor, we found that the smallest cells had the highest density. Previous studies have suggested that the CFE correlates with the density of the $\beta 1$-integrin receptor and not the cell size in the basal layer cells [2]. We found that the CFE not only correlated with the $\beta 1$ integrin receptor density but also correlated with the cell size in the RA cell population. Although still controversial, much evidence has shown that various tissuespecific stem cells can develop into the cells of unrelated tissue [43-45]. Liang et al. [46] reported that murine EpSCs can develop into cells of multiple cell lineages. In this study, we found that population A cells lost their $\beta 1$-integrin expression in murine blastocysts. Unlike in suspension culture, involucrin expression did not appear in population A cells, suggesting that population A cells did not undergo terminal differentiation in murine blastocysts. We detected human donor cells in day 13.5 mouse embryonic tissues derived from blastocysts injected with cells from population A. By contrast, relatively few positive signals were observed in embryonic tissues derived from blastocysts injected with cells from population B and populations $\mathrm{C}$. In addition, we found that the human donor cells were distributed among several murine tissue types. These data suggest that the smallest cells in the RA cells possess the greatest proliferation and differentiation potential during development. Because some reports have shown that several types of cells can adopt the phenotypes of other cells by cell fusion [47-49], we cannot completely rule out the possibility that these donor cells were the product of cell fusion. Collectively, our data show that cells from population A exhibit many traits of adult stem cells and are enriched for human EpSCs.

We have demonstrated that cell size combined with collagen type IV adhesiveness could enrich for a subpopulation of epidermal cells that exhibit more features of EpSCs. We provided an alternative approach to enrich EpSCs in addition to the use of cell markers of $\alpha 6^{\text {bri }} \mathrm{CD}$ - 
$71^{\mathrm{dim}}$ and $\beta 1^{\text {bri }} \mathrm{Dsg} 3^{\mathrm{dim}}$. All of these approaches use one of the integrin subunits ( $\beta 1$ or $\alpha 6)$ as the positive parameter and a second parameter (cell size, Dsg3 or the differentiation-related marker CD71) as the negative parameter to enrich EpSCs. However, unlike the other two approaches, our study did not use antibodies to enrich human EpSCs. Antibodies are known to alter the physiology of some cell types $[50,51]$. A recent report has suggested that antibody-based stem cell isolation procedures have negative effects on the physiology of hematopoietic stem cells (HSCs) [50]. HSCs that were incubated with the antibody cocktail had decreased expression of the stem cell-associated genes and diminished ability to confer long-term hematopoietic engraftment in lethally irradiated mice [50]. In this study, we found that human putative EpSCs enriched according to our improved strategy survived better than $\beta 1$-IBCPIAF cells. Although there was no evidence that antibody has a negative effect on EpSCs, our approach presented here could rule out this possibility.

In conclusion, our study provides a putative strategy to isolate a subpopulation of keratinocytes that contains EpSCs, and encourages further study into the role of cell size in stem cell biology. In addition, our data have important implications for the study of the plasticity of EpSCs. EpSCs are likely to provide a source of a diverse range of cell types. Finally, the accessibility of skin tissue makes human EpSCs an ideal vehicle for skin tissue engineering. This improved strategy for the identification and enrichment of these cells represents an important prerequisite for development in this field.

\section{Materials and Methods}

\section{Primary human keratinocyte preparation}

Aborted human fetuses ( $N=15$, aged $\geq 20$ weeks) were collected from a local hospital. The use of human tissue in this project was approved by the Ethical Committee of the Institute of Zoology, Chinese Academy of Science. Basal keratinocytes were harvested as described elsewhere $[13,46]$. In brief, skin samples from human fetuses were incubated in $0.25 \%$ trypsin with $0.02 \%$ EDTA overnight at $4{ }^{\circ} \mathrm{C}$. Basal cells from the interfollicular epidermis were dissociated into single-cell suspension by gently shaking the epidermis sheet in Dubecco's modified Eagle's medium containing $10 \%$ fetal calf serum (FCS) (Hyclone, Utah, USA) and $100 \mathrm{IU} / \mathrm{ml}$ of gentamicine, streptomycin and penicillin.

\section{$R A$ cell preparation and flow cytometry analysis}

The keratinocyte adhesion procedure was performed as previously described [31]. Culture dishes $(100 \mathrm{~mm})$ were prepared by coating with $20 \mu \mathrm{g} / \mathrm{ml}$ collagen type IV (Sigma, St Louis, USA) overnight at $4{ }^{\circ} \mathrm{C}$. The basal cells harvested from the interfollicular epidermis were separated according to the adherent time to collagen type IV. In brief, $5 \times 10^{6}$ human primary keratinocytes were suspended in $10 \mathrm{ml}$ FD (Dubecco's modified Eagle's medium and Ham's F-12 medium, at a ratio of 3:1) culture medium supplemented with $10 \%$ FCS and incubated in a collagen type IV-coated dish for $20 \mathrm{~min}$ at $37^{\circ} \mathrm{C}$. Then the culture medium with nonadherent cells was carefully removed from the dish using a transfer pipette and placed into a $10 \mathrm{ml}$ tube. To wash off the remaining non-adherent cells in the dish, $5 \mathrm{ml}$ of culture media were carefully added to the dish and gently agitated for $10 \mathrm{~s}$. Again, the medium with non-adherent cells was removed and placed into another 10 $\mathrm{ml}$ tube. The dish was washed twice. The remaining cells in the dish were trypsinized and collected as RA cells. The non-adherent cells in the tube were centrifuged at 1000 r.p.m for 5 min and resuspended in $10 \mathrm{ml} \mathrm{FD} \mathrm{culture} \mathrm{medium} \mathrm{with} 10 \%$ FCS. Again, the non-adherent cells were transferred to another collagen type IVcoated dish and allowed to adhere for $12 \mathrm{~h}$. Similarly, the adherent cells were collected as SA cells and the NA cells were collected as well.

The light-scattering properties of the keratinocytes were measured in a flow cytometer (Franklin Lakes, NJ, USA) using an Argon laser (488 $\mathrm{nm}$ ) as the probing beam. The FSC distribution histograms for each cell population were generated on computer from raw data files of flow cytometry.

\section{Cell diameter measurement and cell sorting by flow cytom-} etry

The diameters of the RA cells were measured under a microscope (Nikon, NY, USA) at a magnification of $\times 400$. In each independent experiment, about 1000 cells were measured. The number and percentages of cells in the different cell size categories ( 5 to 7 $\mu \mathrm{m}, 7$ to $9 \mu \mathrm{m}$, and $\geq 9 \mu \mathrm{m}$ ) were counted. The percentages of cells in each cell size category were $21.6 \pm 1.23 \%, 60.6 \pm 2.57 \%$ and $17.3 \pm 1.42 \%$, respectively.

Cell sorting was carried out according to a similar, previously described method with some modifications [29]. In brief, a 488-nm argon laser was used as the probing beam. RA cells were separated on the basis of their FSC profile, which is an indirect measurement of cell size. Before sorting, 10000 events were collected for analysis. Ensuring that cell debris was not included, we gated the main cell population and separated the main population gate into three sub-gates (A, B and C). In each sub-gate, the percentage of cells in relation to the total cells of main population was adapted to $21.6 \%, 60.6 \%$ and $17.3 \%$, respectively. We then maintained all the parameters of the flow cytometer to remain unchanged. The cells within each sub-gate limit were sorted and collected, representing the different cell size ranges: 5 to $7 \mu \mathrm{m}$ (population A), 7 to $9 \mu \mathrm{m}$ (population B) and $\geq 9 \mu \mathrm{m}$ (population C). For some experiments, the diameter of cells sorted from each subpopulation was measured under a microscope.

\section{Cell viability assay}

In an adherence assay, sorted keratinocytes were seeded on collagen type IV-coated $(20 \mu \mathrm{g} / \mathrm{ml})$ 96-well culture plates. Viable keratinocytes that had adhered within $12 \mathrm{~h}$ were counted and were recorded as relative percentages of the total number of keratinocytes initially seeded. In a short-term cell proliferative assay, sorted keratinocytes were seeded into feeder cell free 24-well plates. The seeding density was $10^{5}$ cells per well. The cell outputs were counted every 2 days for 10 days. 


\section{Immunohistochemistry and immunocytochemistry}

Human fetal skin samples were harvested and stored at $-80{ }^{\circ} \mathrm{C}$. For mouse embryos, day 13.5 embryos were soaked in $30 \%$ sucrose at $4{ }^{\circ} \mathrm{C}$ overnight, kept frozen in liquid nitrogen and stored at $-80{ }^{\circ} \mathrm{C}$. Eight micrometer sections were made on a cryostat, and slides were stored at $-80{ }^{\circ} \mathrm{C}$. To assess the immunohistochemistry, sections were fixed in $4 \%$ paraformaldehyde for $1 \mathrm{~h}$ at room temperature, rinsed with phosphate-buffered saline (PBS) three times and treated with $0.1 \%$ Triton X-100 for $10 \mathrm{~min}$ at room temperature. After blocking with $10 \%$ bovine serum albumin (BSA) in PBS for $60 \mathrm{~min}$, sections were incubated with a primary antibody (diluted in $3 \% \mathrm{BSA} / \mathrm{PBS}$ ) overnight at $4{ }^{\circ} \mathrm{C}$. The primary antibodies were p63 (Santa Cruz, 1:100, CA, USA) and anti-human nuclei antibody (Chemicon, 1:50, CA, USA). After washing with PBS three times, sections were incubated with the appropriate fluorescein isothiocyanate-labeled secondary antibodies (1:100) for $1 \mathrm{~h}$ at $37{ }^{\circ} \mathrm{C}$, followed by counterstaining with propidium iodide (PI, Sigma, St Louis, USA) for $10 \mathrm{~min}$ at room temperature. Sections were examined and photographed under a confocal microscope (Leica, Heidelberg, Germany). To assess the immunocytochemistry, the fractionated cells were stained according to the steps described above for immunohistochemistry. A similar procedure was used for injected blastocysts, except that the blastocysts were counterstained with Hoechst (Sigma, St Louis, USA). The primary antibodies used in the immunocytochemical analysis were p63, $\beta 1$-integrin and involucrin (Santa Cruz, 1:100, CA, USA).

\section{Cell-cycle analysis and transmission electron microscopy}

Sorted cells were collected and fixed in $70 \%$ ethanol overnight at $4{ }^{\circ} \mathrm{C}$, washed with PBS and incubated with $50 \mu \mathrm{g} / \mathrm{ml}$ RNase, 40 $\mu \mathrm{g} / \mathrm{ml}$ PI and $0.1 \%$ Triton X-100 for $30 \mathrm{~min}$ at $37{ }^{\circ} \mathrm{C}$. DNA content was measured using an excitation wavelength of $488 \mathrm{~nm}$ and an emission wavelength of $635 \mathrm{~nm}$, and analyzed using the ModFit software program.

During the electron microscopic analysis, sorted epidermal cells were fixed in freshly prepared fixative solution (4\% paraformaldehyde and 2\% glutaraldehyde in PBS) for $1 \mathrm{~h}$. After post-fixation with $1 \% \mathrm{OsO}_{4}$ in cacodylate buffer for $1 \mathrm{~h}$ at $4{ }^{\circ} \mathrm{C}$, the samples were dehydrated in graded ethanol and embedded in Epon. Sections were cut using an ultramicrotome (Leica, Heidelberg, Germany) and stained with a saturated solution of uranyl acetate in acetone, followed by a solution of $0.2 \%$ lead citrate, and then observed under a transmission electron microscope (Jeol,Tokyo, Japan).

\section{CFE assay}

To evaluate the proliferative potential of isolated cells, the CFE was assessed as described previously [2]. In brief, an equivalent number of separated cells (500 cells/plate) were co-cultured with human dermal-derived fibroblasts treated with mitomycin C (Sigma, St Louis, USA) in FD culture medium (Dubecco's modified Eagle's medium and Ham's F-12 medium, at a ratio of 3:1) supplemented with $10 \%$ FCS, $10 \mathrm{ng} / \mathrm{ml}$ epidermal growth factor (Sigma), $5 \mu \mathrm{g} / \mathrm{ml}$ transferrin (Sigma), $0.18 \mathrm{nM}$ adenine (Amresco, $\mathrm{OH}$, USA), $5 \mu \mathrm{g} / \mathrm{ml}$ insulin (Sigma), $1 \mathrm{nM}$ cholera toxin (Sigma) and 0.4 $\mathrm{ig} / \mathrm{ml}$ hydrocortisone (Sigma) for 2 weeks. The colonies were fixed with $4 \%$ formaldehyde and stained with $1 \%$ rhodamine B (Sigma) and the colony numbers were counted under a microscope. Only the colonies that contained more than 32 cells were scored.

\section{Suspension-induced terminal differentiation}

Suspension-induced terminal differentiation was carried out as previously described [13]. In brief, the sorted cells were placed in FD culture medium containing $1.6 \%$ methyl cellulose (Sigma, St Louis, USA). After culture for $24 \mathrm{~h}$ at $37{ }^{\circ} \mathrm{C}$, the cells were harvested and used for immunocytochemical analysis.

\section{Micro-injection of RA cells into blastocysts}

To micro-inject RA cells into blastocysts, 5-8-week-old Kunming white female mice were superovulated with $10 \mathrm{U}$ of pregnant mare serum gonadotrophin and 46-48 h later with $10 \mathrm{U}$ of human choriogonadotropin (hCG). Superovulated females were mated with Kunming white males after hCG injection and the appearance of a vaginal plug was confirmed the next day (day 0.5 of gestation). At day 3.5 of gestation, the females were sacrificed and the uterine tracts were isolated and flushed with M2 medium. The blastocysts were collected and incubated in a cell culture medium modified by Chatot CL, Ziomek CA, Bavister BD (CZB medium) at $37^{\circ} \mathrm{C}$.

For analysis in vitro, cells from population A were stained with the red fluorescent dye PKH26 (Sigma, St Louis, USA), according to the staining protocol of the supplier (Sigma), and injected into blastocysts. Each blastocyst was injected with 20-25 cells. Injected blastocysts were grouped and cultured in CZB medium for different lengths of time $(0,24$ and $72 \mathrm{~h})$. Blastocysts were then harvested for immunocytochemical analysis. For analysis in vivo, cells from population $\mathrm{A}$, population $\mathrm{B}$ and population $\mathrm{C}$ were injected into separate blastocysts. Each blastocyst was injected with 20-25 cells. About 12 injected blastocysts were transferred to the uterus of each pseudo-pregnant recipient mother. At embryonic day 13.5, embryos were harvested from the uterus of each pregnant mouse for analysis. Some recipient mothers gave birth to pups. These pups were bred in an animal care center and allowed to develop to adulthood.

\section{Polymerase chain reaction (PCR) analysis}

Embryos were harvested and washed in PBS. A single embryo was digested with proteinase $\mathrm{K}$ and DNA was extracted through phenol/chloroform purification and isopropanol precipitation. To analyze the adult tissues, various tissues were harvested from chimeric mice at the age of 2 months. Here, the DNA extraction procedure was the same as that used for the embryos. The presence of human-specific-DNA was detected by PCR amplification of a 479-bp fragment of a highly repetitive $\alpha$-satellite DNA sequence of the centromere region of human chromosome 17, with primers modified according to Becker (5'-GGG ATA ATT TCA GCT GAC TAA ACA G-3'; 5'-AAA CGT CCA CTT GCA GTT CTA G-3') [52]. DNA samples from human skin as a positive control and normal Kunming white mouse 13.5 day embryos or tissue as a negative control were processed in parallel.

\section{Statistical analysis}

Statistical differences were evaluated using Student's $t$-test or analysis of variance (ANOVA). The data were presented as the mean \pm S.D. from at least three independent experiments.

\section{Acknowledgments}

We thank all volunteers for kindly providing samples, 
Dr Aaron J W Hsueh (Stanford University School of Medicine, USA) and Dr Wang Fei (Institute for Genomic Biology, University of Illinois at Urbana-Champaign) for critical reading of the manuscript, and Xiao-Hua Lei (Northwest A \& F University, China) for mouse blastocyst collection. This work was supported by the National Basic Research Program of China (2006CB0F1006) and the National Natural Science Foundation of China (30570709).

\section{References}

1 Watt FM. Epidermal stem cells: marker, patterning and the control of stem cell fate. Philos Trans R Soc London B 1998; 353:831-837.

2 Jones PH, Watt FM. Separation of human epidermal stem cells from transit amplifying cells on the basis of differences in integrin function and expression. Cell 1993; 73:713-724.

3 Lajtha LG. Stem cell concepts. Differenation 1979; 14:23-34.

4 Clayton E, Doupe DP, Klein AM, Winton DJ, Simons BD, Jones $\mathrm{PH}$. A single type of progenitor cell maintains normal epidermis. Nature 2007; 446:185-189.

5 Bickenbach JR, Stern MM, Grinnell KL, Manuel A, Chinnathambi S. Epidermal stem cells have the potential to assist in healing damaged tissues. J Invest Dermatol Symp Proc 2006; 11:118-123.

6 Motlik J, Klima J, Dvorankova B, Smetana K Jr. Porcine epidermal stem cells as a biomedical model for wound healing and normal/malignant epithelial cell propagation. Theriogenology 2007; 67:105-111.

7 Chebotaev D, Yemelyanov A, Zhu L, Lavker RM, Budunova I. The tumor suppressor effect of the glucocorticoid receptor in skin is mediated via its effect on follicular epithelial stem cells. Oncogene 2007; 26:3060-3068.

8 Spoler F, Forst M, Marquardt Y, et al. High-resolution optical coherence tomography as a non-destructive monitoring tool for the engineering of skin equivalents. Skin Res Technol 2006; 12:261-267.

9 Andreadis ST. Gene-modified tissue-engineered skin: the next generation of skin substitutes. Adv Biochem Eng Biotechnol 2007; 103:241-274.

$10 \mathrm{Li} \mathrm{A}$, Simmons PJ, Kaur P. Identification and isolation of candidate human keratinocyte stem cells based on cell surface phenotype. Proc Natl Acad Sci USA 1998; 95:3902-3907.

11 Wan H, Stone MG, Simpson C, et al. Desmosomal proteins, including desmoglein 3, serve as novel negative markers for epidermal stem cell containing population of keratinocytes. $J$ Cell Sci 2003; 116:4239-4248.

12 Tani H, Morris RJ, Kaur P. Enrichment for murine keratinocytes stem cells based on cell surface phenotype. Proc Natl Acad Sci USA 2000; 97:10960-10965.

13 Zhou JX, Chen SY, Liu WM, Cao YJ, Duan EK. Enrichment and identification of human 'fetal' epidermal stem cells. Hum Reprod 2004; 19:968-974

14 Li DQ, Chen Z, Song XJ, de Paiva CS, Kim HS, Pflugfelder SC. Partial enrichment of a population of human limbal epithelial cells with putative stem cell properties based on collagen type IV adhesiveness. Exp Eye Res 2005; 80:581-590.
15 Jones PH, Harper S, Watt FM. Stem cell patterning and fate in human epidermis. Cell 1995; 80:83-93.

16 Potten, CS, Morris RJ. Epithelial stem cells in vivo. J Cell Sci Suppl 1988; 10:45-62.

17 Kaur P, Li A. Adhesive properties of human basal epidermal cells: an analysis of keratinocyte stem cells, transit amplifying cells, and postmitotic differentiating cells. J Invest Dermatol 2000; 114:413-420.

18 Li A, Pouliot N, Redvers R, Kaur P. Extensive tissue-regenerative capacity of neonatal human keratinocyte stem cells and their progeny. J Clin Invest 2004; 113:390-400.

19 Redvers RP, Li A, Kaur P. Side population in adult murine epidermis exhibits phenotypic and functional characteristics of keratinocyte stem cells. Proc Natl Acad Sci USA 2006 103:13168-13173.

20 Larderet G, Fortunel NO, Vaipgot P, et al. Human side population keratinocytes exhibit long-term proliferative potential and a specific gene expression profile and can form a pluristratified epidermis. Stem Cells 2006; 24:965-974.

21 Yano S, Ito Y, Fujimoto M, Hamazaki TS, Tamaki K, Okochi $\mathrm{H}$. Characterization and localization of side population cells in mouse skin. Stem Cells 2005; 23:834-841.

22 Terunuma A, Kapoor V, Yee C, Telford WG, Udey MC, Vogel JC. Stem cell activity of human side population and alpha6 integrin-bright keratinocytes defined by a quantitative in vivo assay. Stem Cells 2007; 25:664-669.

23 Triel C, Vestergaard ME, Bolund L, Jensen TG, Jensen UB. Side population cells in human and mouse epidermis lack stem cell characteristics. Exp Cell Res 2004; 295:79-90.

24 Gao FB, Raff M. Cell size control and a cell-intrinsic maturation program in proliferating oligodendrocyte precursor cells. J Cell Biol 1997; 138:1367-1377.

25 Barrandon Y, Green H. Cell size as a determinant of the cloneforming ability of human keratinocytes. Proc Natl Acad Sci USA 1985; 82:5390-5394.

26 Angello JC, Pendergrass WR, Norwood TH, Prothero J. Proliferative potential of human fibroblasts: an inverse dependence on cell size. J Cell Physiol 1987; 132:125-130.

27 Watt FM, Green H. Involucrin synthesis is correlated with cell size in human epidermal cultures. J Cell Biol 1981; 90:738-742

$28 \mathrm{Qu}$ Z, McClellan WR, Weiss JN. Dynamics of the cell cycle: checkpoints, sizers, and timers. Biophys $J$ 2003; 85:3600-3611.

29 De Paiva CS, Pflugfelder SC, Li DQ. Cell size correlates with phenotype and proliferative capacity in human corneal epithelial cells. Stem Cells 2006; 24:368-375.

30 Pellegrini G, Dellambra E, Golisano O, et al. P63 identifies keratinocyte stem cells. Proc Natl Acad Sci USA 2001; 98:3156-3161.

31 Kim DS, Cho HJ, Choi HR, Kwon SB, Park KC. Isolation of human epidermal stem cells by adherence and the reconstruction of skin equivalents. Cell Mol Life Sci 2004; 61:2774-2781.

32 Parsa R, Yang A, McKeon F Green H. Association of p63 with proliferative potential in normal and neoplastic human keratinocytes. J Invest Dermatol 1999; 113:1099-1105.

33 Dazard JE, Piette J, Basset-Seguin N, Blanchard JM, Gandarillas A. Switch from p53 to MDM2 as differentiating human keratinocytes lose their proliferative potential and increase in cellular size. Oncogene 2000; 19:3693-3705. 
34 Tseng H, Green H. Association of basonuclin with ability of keratinocytes to multiply and with absence of terminal differentiation. J Cell Biol 1994; 126:495-506.

35 Poot M, Rizk-Rabin M, Hoehn H, Pavlovitch JH. Cell size and RNA content correlate with cell differentiation and proliferative capacity of rat keratinocytes. J Cell Physiol 1990; 143:279-286.

36 Blau HM, Brazelton TR, Weimann JM. The evolving concept of a stem cell: entity or function? Cell 2001; 105:829-841.

37 Watt FM, Hogan BL. Out of Eden: stem cells and their niches. Lavker RM, Sun TT. Epidermal stem cells: properties, markers, and location. Proc Natl Acad Sci USA 2000; 97:13473-13475.

38 Lavker RM, Sun TT. Epidermal stem cells: properties, markers, and location. Proc Natl Acad Sci USA 2000; 97:13473-13475.

39 Morris RJ, Fischer SM, Slaga TJ. Evidence that the centrally and peripherally located cells in the murine epidermal proliferative unit are two distinct cell populations. J Invest Dermatol 1985; 84:277-281.

40 MacKenzie IC, Bickenbach JR. Label-retaining keratinocytes and Langerhans cells in mouse epithelia. Cell Tissue Res 1985; 242:551-556.

41 Bickenbach JR, McCutecheon J, MacKenzie IC. Rate of loss of tritiated thymidine label in basal cells in mouse epithelial tissues. Cell Tissue Kinet 1986; 19:325-333.

42 Morris RJ, Potten CS. Slowly cycling (label-retaining) epidermal cells behave like clonogenic stem cells in vitro. Cell Prolif 1994; 27:279-289.

43 Fougere-Deschatrette C, Imaizumi-Scherrer T, et al. Plasticity of hepatic cell differentiation: bipotential adult mouse liver clonal cell lines competent to differentiate in vitro and in vivo.
Stem Cells 2006; 24:2098-2109.

44 Croft AP, Przyborski SA. Formation of neurons by non-neural adult stem cells: potential mechanism implicates an artifact of growth in culture. Stem Cells 2006; 24:1841-1851.

45 Wislet-Gendebien S, Hans G, Leprince P, Rigo JM, Moonen G, Rogister B. Plasticity of cultured mesenchymal stem cells: switch from nestin-positive to excitable neuron-like phenotype. Stem Cells 2005; 23:392-402.

46 Liang L, Bickenbach JR. Somatic epidermal stem cells can produce multiple cell lineages during development. Stem Cells 2002; 20:21-31.

47 Wang X, Willenbring H, Akkari Y, et al. Cell fusion is the principal source of bone marrow derived hepatocytes. Nature 2003; 422:897-901.

48 Terada N, Hamazaki T, Oka M, et al. Bone marrow cells adopt the phenotype of other cells by spontaneous cell fusion. Nature 2002; 416:542-545.

49 Ying QL, Nichols J, Evans EP, Smith AG. Changing potency by spontaneous fusion. Nature 2002; 416:545-548.

50 Gilner JB, Walton WG, Gush K, Kirby SL. Antibodies to stem cell marker antigens reduce engraftment of hematopoietic stem cells. Stem Cells 2007; 25:279-288.

51 Shapiro AM, Jack CS, Lapierre Y, Arbour N, Bar-Or A, Antel JP. Potential for interferon beta-induced serum antibodies in multiple sclerosis to inhibit endogenous interferon-regulated chemokine/cytokine responses within the central nervous system. Arch Neurol 2006; 63:1296-1299.

52 Becker M, Nitsche A, Neumann C, Aumann J, Junghahn I, Fichtner I. Sensitive PCR method for the detection and realtime quantification of human cells in xenotransplantation systems. Br J Cancer 2002; 87:1328-1335. 